\title{
Research on Employee Participation System
}

\author{
Jianduan Li \\ School of Management, Wuhan University of Technology, Wuhan 430000, China \\ 616268693@qq.com
}

\begin{abstract}
Since the reform and opening up, China has made great achievements in economic construction. However, with China is entering into the "new normal" of the economy, the competition of enterprises is increasing and the pressure of development is increasing. The development of employee participation system and culture in our country lags far behind the western developed countries, this result in a high turnover rate, low employee motivation and low employee satisfaction. Based on the literature research of domestic and foreign scholars, according to Maslow's hierarchy of needs, this paper analyzes the significance and necessity of employee participation system, and analyzes the significance and necessity of employee participation system.
\end{abstract}

Keywords: Employee participation, Employee participation system, Employee motivation, Maslow demand theory.

\section{Introduction}

Since the middle of $80 \mathrm{~s}$, in the western developed countries, enterprises are increasingly aware of the traditional management methods to adapt to the development of the market. Therefore, these enterprises have adopted a new management approach that is to participate in staff to enhance employee satisfaction, loyalty and decision-making level, and provide important support for the healthy development of enterprises. Chinese economic has a rapid development since the reform and opening up. However, due to the characteristics of their own economy, the larger proportion of state-owned components and other reasons, the development of enterprise employee participation system lags behind many developed countries. With the 1980s after the birth of the new generation of employees into the workplace and become the main force in the workplace, they experienced a market economy and economic globalization, the wave of information, compared to the old employees more personality and self-consciousness, participation intention and demand more intense. It also puts forward the challenge and opportunity for the enterprises under the new normal economy in our country, and it is imperative to strengthen the staff participation and the establishment of employee participation system.

\section{Demand and Incentive Analysis}

The mobilization of organizational members of the initiative is an eternal theme for every enterprise. In other words, the incentive is always needed. For the "people" who are members of the organization, the most essential way to stimulate their enthusiasm is to meet their needs. In other words, to meet people's needs, is the most basic means of motivating employees ${ }^{[1]}$. The research on the needs of people has a long history, and there were thousands of works for it already. However, the works has a similar result which is the human needs are hierarchical. The famous typical representative is the Maslow's "The five-level theory of demand" ${ }^{[2]}$.

American social psychologist Maslow thinks that the needs of people are different levels, and he set the famous "five- level theory of demand".

(1)The physiological needs: This is the human to maintain their own survival of the most basic requirements, including hunger, thirst, clothing, living, sexual and other requirements. If these needs are not met, the survival of mankind becomes a problem. In this sense, physical needs are the most powerful driving force for people to act. 
(2)The need for security: This is the human requirements to protect their own security, get rid of the cause and loss of property threats, to avoid the invasion of occupational diseases, contact with the harsh supervision and other needs.

(3)Emotional needs: The needs of this level include two aspects of the content. First, the need for friendship, that everyone needs partners, the relationship between colleagues harmonious or maintain friendship and loyalty; second, the need for attribution, people has a belonging to a group of feelings; want to become a member of the group, and mutual care and care.

(4)Respect for the need: The need for respect can be divided into internal respect and external respect. Internal respect refers to a person who wishes to be capable, competent, confident and independent in a variety of situations. In short, internal respect is human self-esteem. External respect refers to a person who wants to have status, prestige, by others respect, trust and highly appraised.

(5)Self-actualization needs: This is the highest level of needs. It refers to the realization of personal ideals, aspirations, to play the individual's ability to the greatest degree of completion of their ability to commensurate with all the needs.

According to different perspectives, the above five levels of demand can be different classification. According to the material and non-materialistic demand, the first two of the five are called "material needs", and the latter three are called "spiritual needs". According to the needs of the basic and development of the points, the first three are known as the "lack of demand", also known as low-level demand, only to meet these needs, the individual felt the basic comfort. The latter two are called "growth demand", also known as high-level demand, once meet these needs, the individual will feel happy.

Research show the people found that everyone has the "lack of demand". However the "growth need"is not necessary for all.

\section{Staff participation system}

As human needs can be divided into material needs and spiritual needs, the incentives can also be divided to material incentives and spiritual incentives. Material incentives are commonly used to pay incentives, bonus incentives, physical incentives, welfare incentives, options incentives, which has been proved by others. There are many spiritual incentives, this article only talk about the staff participation system of this incentive ${ }^{[3]}$.

Employee participation is a democratic management system, but due to it can meet the needs of an employee's expression, achievement needs and participation needs, therefore, it can also be used as a way of incentive. In the labor relations, employees are workers who use labor in exchange for income, from the market point of view; this is an exchange ${ }^{[4,5]}$. But the staff is also human. From the human nature of the point of view, employees have the labor in exchange for the survival of the material needs of this aspect, but from the social properties of the staff point of view, employees also have the needs of access to group recognition, personal achievement, highlighting personal values, and respect by others. And these are precisely the focus of spiritual motivation ${ }^{[6]}$. There are many ways to inspire the spirit, such as recognition, winning, promotion, etc., the staff participation system is to stimulate the lower cost, but the effect is good ${ }^{[7]}$. Enterprise employees have the following practices.

(1)Participate In Improvement. Employee participation is the most basic and extensive employee participation system. An enterprise needs to improve the place can be said to be everywhere, and the staff is widely distributed, they are directly into the enterprise production, management, business aspects of all aspects of the enterprise is a direct participant of all activities, they know the situation, they have the talk rights. Therefore, a wide range of employees used their brains, and actively put forward all aspects of rationalization proposals to improve the production, management, business activities, is much better, the enterprise can benefit from the improvement. And employees involved in activities, will inevitably produce a sense of ownership and achievements, and business sense of identity, work enthusiasm will be fully excited. 
Japanese enterprises QC (Quality control, generally translated as quality management) group activities is a typical example, very successful, for the world attention. QC groups are widely active in Japanese companies, especially in the manufacturing sector. It is usually based on the work group (also can cross-team), to participate in the principle of free, by the voluntary composition of the activities of the staff, regular activities. The contents of the activities of their own operations (but also on the production, management, business and other aspects of the work) to improve the views submitted to the enterprise management. After receiving the views of the enterprise management, the works should be improved as soon as possible in accordance with the views of staff to improve the work. Japan has formed employees to participate in culture, enterprises attach great importance to the improvement of staff comments.

This is the staff to participate in activities, so that the quality of Japanese products in the last century, the sixties and sixties, that is, after a short period of one or two years time, there has been a qualitative leap. "Made in Japan" is the world as a "quality goods" synonymous. At this point, the Japanese products become global, so that the world has become the Japanese market. The Japanese economy took off here.

(2)Participate in supervision. The day-to-day business decision-making business of the enterprise is the responsibility of the board of directors and the enterprise management team, but this does not prevent the people who are responsible for daily business decisions from violating the shareholders' will and even abandoning the interests of the enterprise. This is often said that "insider control". Germany to take the "workers to decide system" is to use the staff to participate in the way to prevent the "insider control" to eliminate a small number of enterprises "elite" abuses of power initiatives. In Germany, to take "workers to decide system" of the enterprise, as long as more than 1,000 employees, corporate supervisors will be representatives of employees and shareholders on behalf of half.

The board of supervisors is a permanent body for the supervision and inspection of the company's financial affairs and the business performance of the board of directors. The Board of Supervisors is in a relatively independent position with the Board of Directors of the Company to prevent the Board from abusing its rights to endanger the interests of shareholders and third parties but not to replace the Board of Directors. The Board of Directors may report on the business situation of the Board of Directors or investigate the business and financial status of the Company at any time, investigate and verify the motion and documents submitted by the Board of Directors to the Shareholders 'General Meeting, supervise and stop the Board of Directors from violating the Statutes and the resolutions of the Shareholders' General Meeting. The board of supervisors system has been implemented in many countries, but its origins are in Germany, and corporate employees to participate in supervisory activities, but also the use of employees in the German enterprises to participate in the supervision of the unique. Obviously, this approach has greatly mobilized the enthusiasm of employees to participate in corporate affairs supervision, and supervision costs are very low.

(3)Involved in management. Employee participation in management as the name implies refers to the day-to-day management of the business activities, so that employees and subordinates involved in the organization's management at all levels, so that lower-level employees and senior management of enterprises in equal position to study and discuss the organization's major problem. In this process, employees can deeply feel the trust and attention of the superior leadership, so as to experience their own interests and organizational development closely related to a strong sense of responsibility and a sense of belonging, greatly meet the staff's emotional needs and respect for the needs The At the same time, participation in management provides employees with a higher platform to show their ability, but also to give employees the opportunity to pay attention to the staff to meet the needs of self-achievement, because employees can participate in discussing their own issues related to excitation. Participation in management provides incentives to individuals and provides a guarantee for the achievement of organizational goals.

Employee participation in the management has a variety of ways, each country has some suitable for their own national conditions and local characteristics of the way. From the foreign situation, since 
the Second World War, Western Europe, Japan, the United States and other Western capitalist countries to revitalize enterprises, to ease labor conflicts, creating a number of workers involved in the way. Such as Sweden to take the management model, etc., that is, the election of workers and staff representatives to participate in the board of directors.

\section{Summary}

To sum up, the success of enterprises cannot be separated from the participation of employees; the establishment of a scientific and systematic staff participation mechanism is the basis for the protection of employee participation. The good operation of employee participation mechanism cannot be separated from the cooperation of enterprise leaders and employees. Enterprises need to have a reasonable sense of empowerment, requiring managers to effectively authorize, enhance staff awareness of the importance of their work, and enhance the sense of responsibility and motivation. At the same time, on the staff level, enterprises should strengthen the management value of employees to participate in the publicity and education work, according to the different types of employees involved in the management status of management and targeted training, strengthen their own strength, improve their comprehensive quality effectively in the enterprise management.

\section{References}

[1]. Jiang Xuexiang, Hu Jiugang. Exploration of enterprise employees' incentive based on Maslow's demand level theory [J], Journal of Educational Science of Hunan Normal University, 2008, 7 (5): 121-123.

[2]. Wang Jiachang. Discussion on the incentive mechanism of state-owned enterprises based on Maslow 's demand level theory [J]. Money China, academic edition, 2009 (2): 39-40.

[3]. Ma Hongmei. The correlation research on corporate employees' participation in management and corporate performance[D], Beijing Chemical University, 2008.

[4]. Zhan Jing, Li Xiaoman. Research review and outlook of foreign employees involved in the system and enterprise performance relationship[J], Human Resources Development of China, 2015 (9): 6-12.

[5]. Zhu Na. Countermeasure analysis of promoting employees' participation in enterprise management [J], Chinese \& Foreign Entrepreneurs, 2014 (13): 186-187.

[6]. Zhu Y, Xie Y, Warner M, et al., Employee participation and the influence on job satisfaction of the "new generation" of Chinese employees [J], International Journal of Human Resource Management, 2014, 26 (19) : 1-17.

[7]. Stephen P Robbins, Robbins, etc. Organizational behavior: the competition strategy of globalization [M], Electronic Industry Press, 2002. 